\title{
On the use of infrared thermography in studies with air curtain devices
}

\author{
Luís P.C. Neto $^{\mathrm{a}, *}$, M.C. Gameiro Silva ${ }^{\mathrm{b}, 1}$, José J. Costa ${ }^{\mathrm{b}, 2}$ \\ ${ }^{a}$ Departamento de Engenharia Industrial, Escola Superior de Tecnologia, Instituto Politécnico de Castelo Branco, \\ Av. do Empresário, 6000-767 Castelo Branco, Portugal \\ ${ }^{\mathrm{b}}$ Departamento de Engenharia Mecânica, Faculdade de Ciências e Tecnologia da Universidade de Coimbra, Pólo II, $3030-290$ Coimbra, Portugal \\ Received 21 May 2005; received in revised form 23 January 2006; accepted 17 February 2006
}

\begin{abstract}
Among the different existing methods to characterise the aerodynamic sealing effect provided by an air curtain device placed over the opening between two contiguous compartments, infrared thermography has revealed to be a very useful tool. Besides allowing the capture, in an expedite way, of instantaneous images of the temperature field in the neighbourhood of the door, the technique hereon described has other advantages, in terms of quick and easy setup, low intrusive character and liability of obtained results.

To apply this method, a large sheet of paper was stretched in the direction perpendicular to the opening where the air curtain device has placed to allow the registration of pictures or video sequences with an infrared camera setup in its maximum sensitivity.

Good concordance between the thermographs obtained with this technique and the temperature fields measured for the same plane with a rack of 16 low velocity omni-directional thermal anemometer probes allowed its validation.

Various elucidative examples of the use of this technique as a complementary tool for analysis and visualization of the complex physical phenomena occurring for the studied flow are presented in this article.
\end{abstract}

(C) 2006 Elsevier B.V. All rights reserved.

Keywords: Infrared thermography; Air curtains; Aerodynamic sealing; Whole-field measuring techniques

\section{Introduction}

In commercial and industrial activities there are often situations where there is a need of reducing or controlling the heat and mass exchanged between the external environment and an enclosure with controlled atmosphere, warranting, simultaneously, an easy circulation of equipments and people between two spaces. In practical terms, confinement of specific indoor environments is usually assured through the utilization of aerodynamic barriers - habitually called air curtains devices (ACD) - constituted by one or more air jets. Needs for the reduction of energetic consumption and a growing demand of comfort by modern societies, create a large number of situations where mounting of this type of device is advised.

Examples of the use practical use of ACD's are found for very diversified situations, such as sealing of the access zones to

\footnotetext{
* Corresponding author. Tel.: +351 272 339300; fax: +351 272339399.

E-mail addresses: luisneto@est.ipcb.pt (Luís P.C. Neto), manuel.gameiro@dem.uc.pt (M.C. Gameiro Silva), jose.costa@dem.uc.pt (J.J. Costa).

${ }^{1}$ Tel.: +351 239 790729; fax: +351 239790771 .

2 Tel.: +351 239 790714; fax: +351239790771.
}

acclimatized commercial or industrial spaces [1,2], protection of doors in industrial refrigerating chambers [3-5], creation of indoor air quality delimited areas [6], barriers to propagation or deposition of pollutants in aggressive work environments [7,8], among others [9].

In a former work from the authors [10] various experimental methods used to evaluate the performances of ACD's were presented. Special attention was given to simultaneous mapping of air velocity and temperature, in the jet development zone and in the neighbourhood of the sealed opening, as a way to understand the physical phenomenon under investigation. However, flow field mapping carried out point by point with low velocity thermal anemometer probes is a very time consuming technique and implies special care on the frequent reposition of test initial conditions that have a tendency to change along the time.

To overcome this inconveniences, it was decide to use a whole-field technique, in sight of visualizing and registering the temperatures of the air in the zone most influenced by the jet generated by the air curtain device. The same method as described in [11] was implemented. The air temperature field is indirectly measured through a low thermal mass screen that is registered by an infrared thermo-graphic camera. This method 


Nomenclature
$\begin{array}{ll}b_{\mathrm{o}} & \text { thickness of air curtain outlet }(\mathrm{m}) \\ D_{\mathrm{m}} & \text { modulus of deflexion } \\ H_{\mathrm{D}} & \text { door height }(\mathrm{m}) \\ \Delta T & \text { temperature difference between two compart- } \\ & \text { ments }\left({ }^{\circ} \mathrm{C}\right) \\ T_{\mathrm{C}} & \text { "cold room" temperature }\left({ }^{\circ} \mathrm{C}\right) \\ T_{\mathrm{W}} & \text { "warm room" temperature }\left({ }^{\circ} \mathrm{C}\right) \\ U_{0} & \text { initial velocity of jet }(\mathrm{m} / \mathrm{s}) \\ W_{\mathrm{D}} & \text { door width }(\mathrm{m}) \\ \text { Greek } & \text { letters } \\ \alpha_{0} & \text { initial angle of air jet }\left({ }^{\circ}\right) \\ \alpha_{\mathrm{f}} & \text { impact angle of jet on the floor }\left({ }^{\circ}\right)\end{array}$

has the main advantage of allowing to obtain, quickly and easily, sequences of instantaneous thermal frames which respond to the effect of the movement of air masses in the studied area.

\section{Experimental setup}

The used facilities comprise two contiguous rooms, with the same dimensions $(6 \mathrm{~m} \times 6 \mathrm{~m} \times 3.27 \mathrm{~m}$, each one $)$, connected each other by an opening with the typical dimensions of a door, with fixed width $\left(W_{\mathrm{D}}=1.12 \mathrm{~m}\right)$ and variable length $\left(2.10 \mathrm{~m}<H_{\mathrm{D}}<2.65 \mathrm{~m}\right)$.

Over the door opening a commercial air curtain device, generating a descending plane air jet, through an outlet with the same width as the door and a thickness $b_{\mathrm{o}}=0.04 \mathrm{~m}$, was mounted. The centre of the jet in the outlet section is $0.06 \mathrm{~m}$ distant from the wall that supports ACD.

One of the rooms was warmed with gas and electric heaters till the predefined temperature $T_{\mathrm{W}}$ for the test in question, while the other one was kept at another lower temperature $T_{\mathrm{C}}$ by an air-conditioning unit. The studied configuration simulates the typical situation of aerodynamic sealing, from the influence of an outside warmer environment, of an acclimatized commercial or domestic room $\left(T_{\mathrm{C}}=20^{\circ} \mathrm{C}\right)$, where it is intended to maintain comfortable conditions.

Before running a test, the door opening was completed sealed with a plastic sheet, which was removed in the beginning of test, being the sealing effect afterward assured by the air curtain device.

\section{Methodology}

As suggested in [11], a sheet of scenery paper, with dimensions $3 \mathrm{~m} \times 2 \mathrm{~m} \times 0.25 \mathrm{~mm}$ was used as measuring screen. It was kept perfectly stretched on the direction perpendicular to the door opening and parallel to the initial direction of the flow (vd. Fig. 1, where the screen location is represented by the vertical measuring grid).

As the studied ACD has two linear fans driven by an electric motor placed in between both, there is not flow in the central plane immediately beneath the device. To overcome this situation the measuring screen was deviated $15 \mathrm{~cm}$ to the right of the central plane, as it was done before when mapping the flow with anemometer probes. An AGEMA THERMOVI-

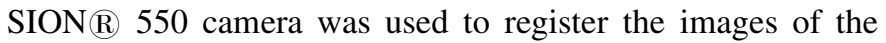
infrared radiation emitted by the screen. This camera has a refrigerated detector, of FPA type, with $320 \times 240$ pixels, with a thermal sensitivity less than $0.1{ }^{\circ} \mathrm{C}$ and sensible to large wave length radiation $(3.6-5 \mu \mathrm{m})$, which is appropriate to detection of temperature levels close to those of indoor environments, when operating in the range between $-20{ }^{\circ} \mathrm{C}$ and $+250{ }^{\circ} \mathrm{C}$.

Infrared radiation emitted by an object is a function of its surface temperature. However, the infrared camera measures, not only this radiation, but also that one coming from the neighbour objects and surfaces and reflected on the surface of the studied object. Other parameters influencing data measured by the camera are the emissivity of the object and the absorption coefficient of the atmosphere. Thus, to measure surface temperatures with precision, it is necessary to compensate the effects of a great number of radiation sources. This can be done automatically and in real time by the camera, if data about the emissivity of studied object, the surrounding temperatures and the distance between the object and the camera are
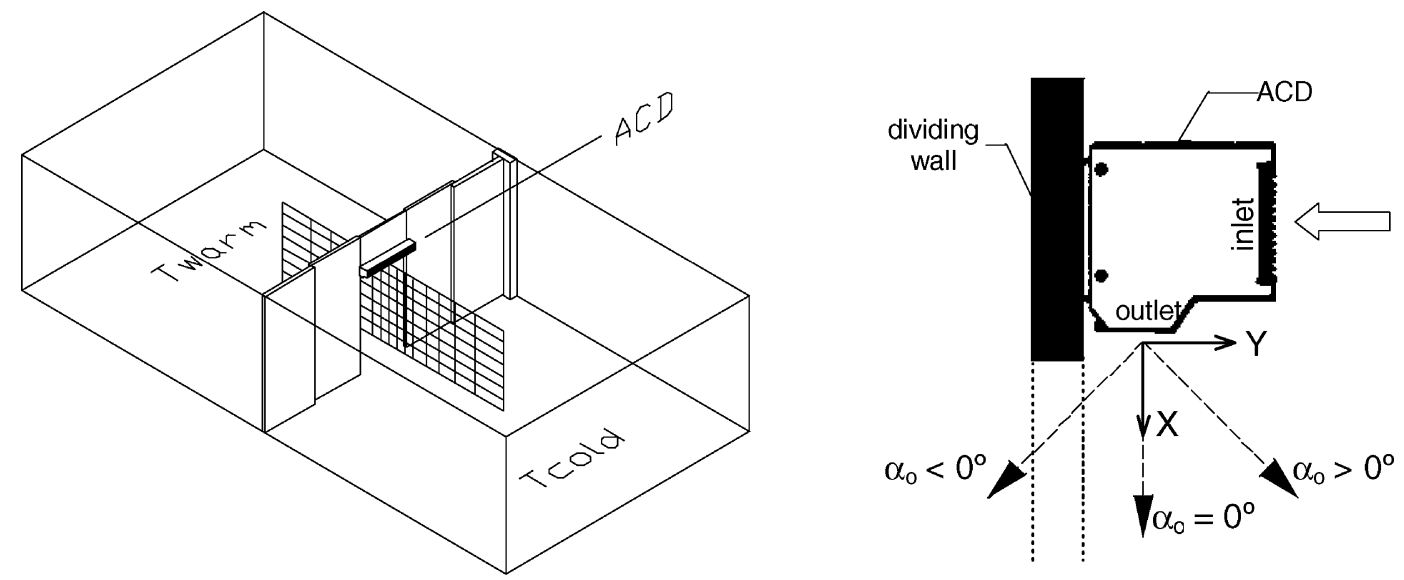

Fig. 1. Scheme of experimental setup and definition of angles and system of axes. 
introduced [12]. To register the thermographic images with the minimum distortion the camera was placed, such as possible, perpendicular to the target screen. In order to identify in the infrared images the localization of the axis of the jet in the exit section and other interest points, small strips of aluminium foil were glued to the screen to serve as marks. The collected 12 bits data files allow the colour or grey scale representation of the screen surface temperature distribution. Using the software supplied with the camera, it is possible to get from the whole image, temperature profiles over straight lines defined by the user or the individual temperature of a given location.

\section{Experimental results}

In Fig. 2, the temperature fields obtained both through the flow field mapping of the vertical plane transversal to the door opening with low velocity thermal anemometer probes and through the registration of infrared thermographic images are represented for the same test conditions.

Both images reveal an initial deflection of the jet to the direction of the compartment where ACD is mounted and confirm that most of the air that is initially dragged from the other room is returned to it at the ground level. This behaviour is typical of this type of devices [13], because the cumulative effects of air injection (generation of pressure difference between the two rooms) and aspiration (impression of a higher angular momentum in the compartment where aspiration takes place) deflect the jet to the compartment where ACD is mounted, even if both rooms are at the same temperature or the jet is vertically discharged $\left(\alpha_{0}=0^{\circ}\right)$.

Results obtained for a situation defined as the reference case, with null sealing efficiency (ACD switched off) is presented in the next figure. Fig. 3a refers to infrared thermography visualization and Fig. $3 \mathrm{~b}$ to isothermal surfaces depicted after the post-processing of data generated by a numerical calculation using a CFD commercial code. The flow pattern is, in this case, dominated by buoyancy effects due to thermal natural convection.

Flow field consists in only one recirculation cell covering all the space of the two rooms, without any restriction other than the one imposed by the dividing wall, as already described in [14], for a 2D numerical calculation performed for an equivalent situation. After [15], sealing capability of a vertical recirculating curtain depends on the equilibrium between the initial momentum of the jet and the transversal forces acting to neutralize its effect. The first frame depicted

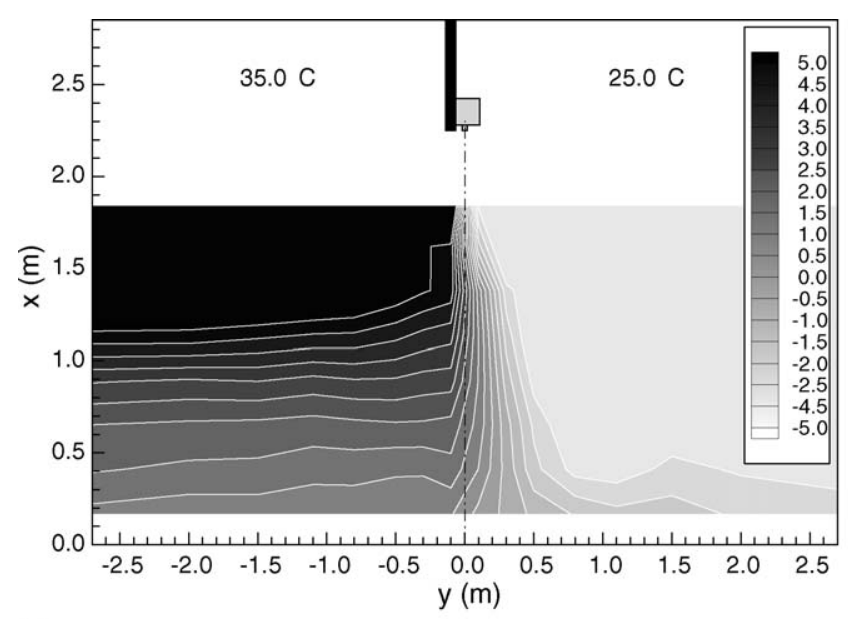

(a)

Mapping with probes

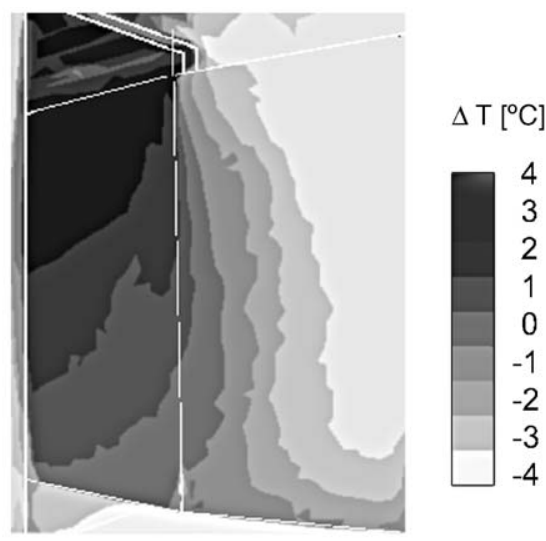

(b) Infrared images

Fig. 2. Temperature distribution along the plane transversal to the door for $U_{0} \approx 5 \mathrm{~m} / \mathrm{s}, H_{\mathrm{D}}=2.10 \mathrm{~m}, \Delta T=10^{\circ}$ and $\alpha_{0}=0^{\circ}$.

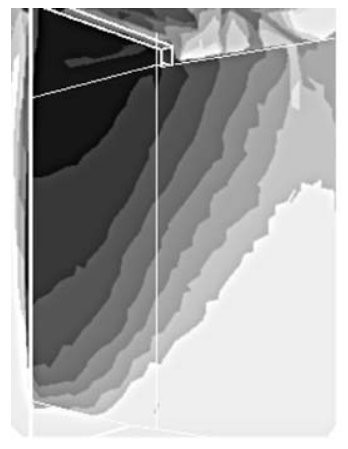

(a) Infrared image

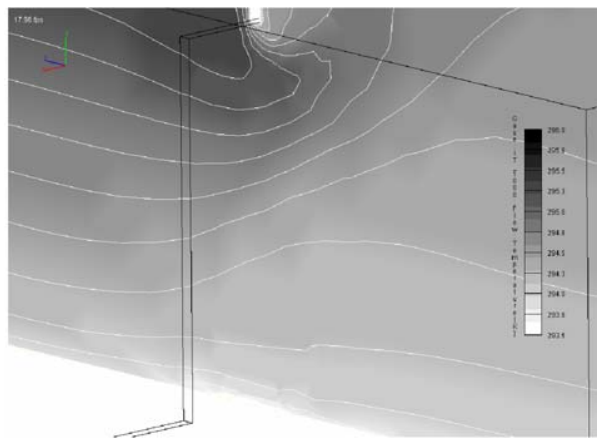

(b) 3D Numerical simulation

Fig. 3. Reference case $\left(U_{0}=0 \mathrm{~m} / \mathrm{s}\right)$ for $H_{\mathrm{D}}=2.40 \mathrm{~m}, \Delta T=10^{\circ} \mathrm{C}, \alpha_{0}=0^{\circ}$. 

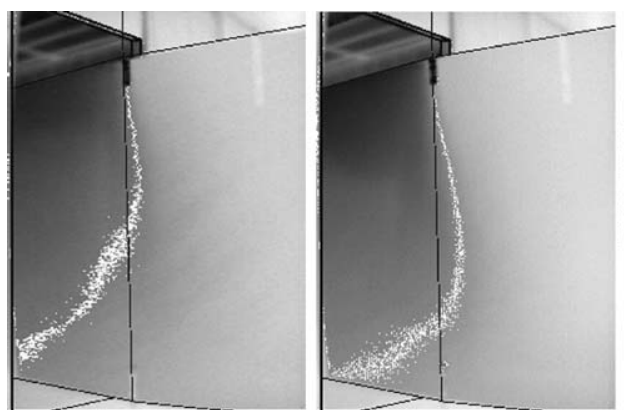

$\mathrm{U}_{\mathrm{o}}=3.4 \mathrm{~m} / \mathrm{s}$

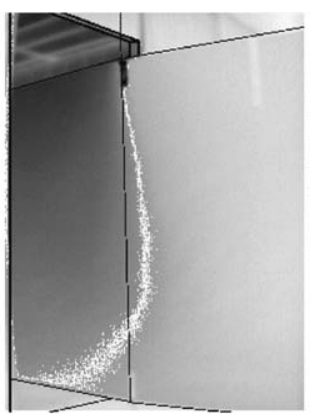

$\mathrm{U}_{0}=6.5 \mathrm{~m} / \mathrm{s}$

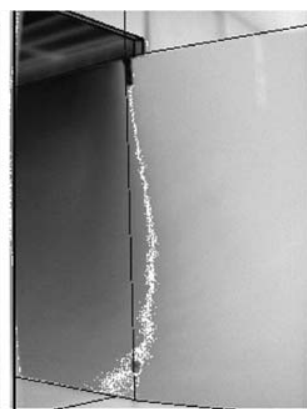

$\mathrm{U}_{0}=8.0 \mathrm{~m} / \mathrm{s}$

Fig. 4. Sequence of thermographs for growing values of initial velocity of the jet, taken 5 min after the beginning of the test, for $H_{\mathrm{D}}=2.65 \mathrm{~m}, \Delta T=15^{\circ} \mathrm{C}, \alpha_{0}=0^{\circ}$.

in Fig. 4 demonstrates what happens when the initial velocity of the jet is too low for the temperature difference existing between the two rooms. As it can be seen, the jet is almost immediately broken and deflected by transversal forces due to thermal buoyancy and do not reach the ground. Tracer gas measurements carried out by the authors [10] for this situation revealed that there is no sealing effect, being, on the contrary, the air exchanges per hour in the cold room in fact $25 \%$ higher than for the reference case, when the ACD was switched off.

The operation of the air curtain becomes more stable as the initial velocity of the jet increases. It is also notorious that the impact area of the jet on the floor tends to come closer to the door-post with increase of velocity, which corroborates the conclusions of [16] after the exact measurement of the jet impact point through horizontal traversing movements performed $10 \mathrm{~mm}$ over the ground with an anemometer probe.

In the pictures depicted in Fig. 5, which were digitally processed to obtain isothermal zones represented in a grey scale, it can be observed that the temperatures gradients become stronger when the initial velocity of the jet increases.

Fig. 6 refers to comparison tests performed with the ACD mounted at different heights, with the same temperature difference between two rooms and the same initial velocity of the jet. Strong deflections of the jet are patent for higher mounting heights, which is a common situation occurring when

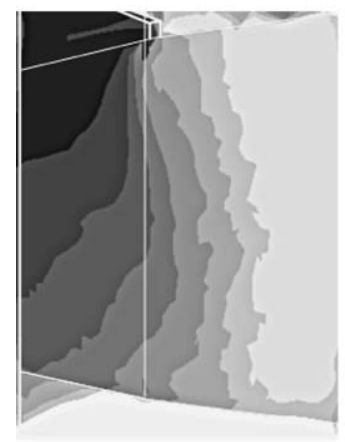

$U_{\circ}=3.6 \mathrm{~m} / \mathrm{s}$

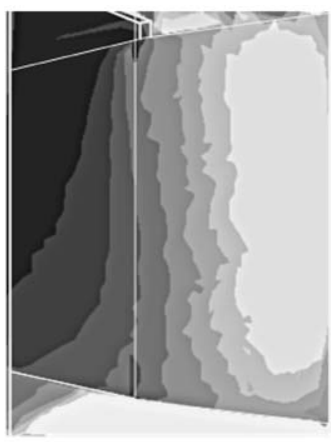

$\cup_{0}=5.6 \mathrm{~m} / \mathrm{s}$
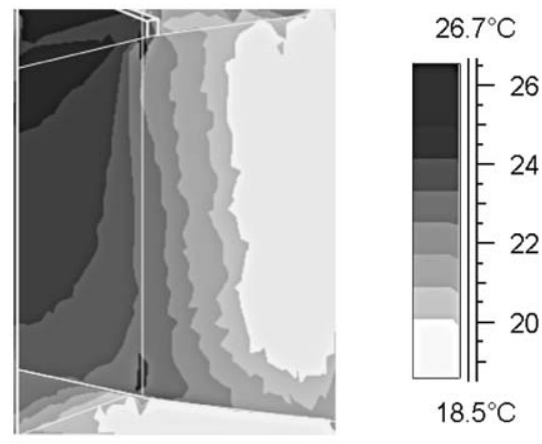

$\mathrm{U}_{\mathrm{o}}=6.8 \mathrm{~m} / \mathrm{s}$

Fig. 5. Evolution of temperature gradients close to the door opening as a function of initial velocity of jet. $H_{\mathrm{D}}=2.40 \mathrm{~m}, T_{\mathrm{C}}=17^{\circ} \mathrm{C}, T_{\mathrm{W}}=27^{\circ} \mathrm{C}, 5 \mathrm{~min}$ after start.

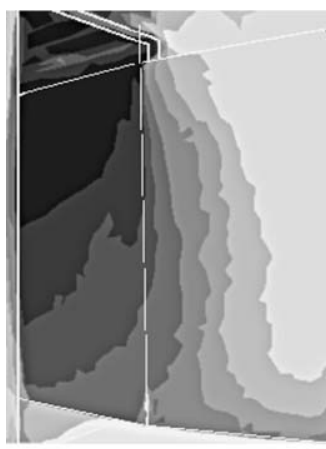

$H_{D}=2.25 m$

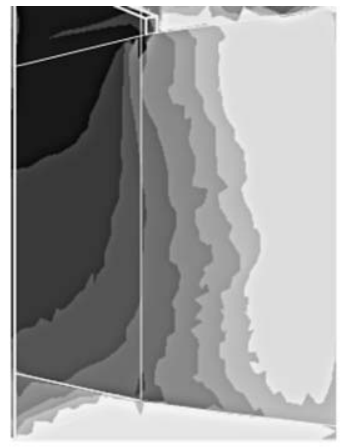

$\mathrm{H}_{\mathrm{D}}=2.40 \mathrm{~m}$
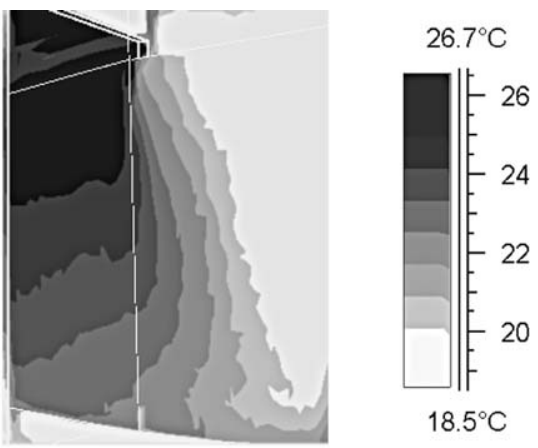

$18.5^{\circ} \mathrm{C}$

Fig. 6. Influence of door height on air jet deflexion, $\Delta T=10^{\circ} \mathrm{C}$ and $U_{0}=4.5 \mathrm{~m} / \mathrm{s}$. 
the initial velocity of the jet is not adjusted as a function of the door opening, as it should be. However, in many cases the fine tuning of the curtain for the existing conditions $\left(\Delta T, H_{\mathrm{D}}\right.$, etc.) is not possible, because only a two or three positions command is available to regulate the fan rotation speed.

According to [17], for the case of ACD's without recirculation, installed in compartments that can be considered hermetical relatively to the outside envelope, there is an optimal momentum of the jet (minimum) that warrants the continuity of the air curtain till the ground and minimizes the heat exchanges through itself.

This optimal working condition corresponds to a minimum of the so-called deflection modulus $D_{\mathrm{m}}$, over which there is a warranty that the air curtain is stable.

When the angle of impact of the flow on the floor $\left(\alpha_{\mathrm{f}}\right)$ is not identical to the initial angle of the jet $\left(\alpha_{0}\right), D_{\mathrm{m}}$ comes:

$$
\begin{aligned}
D_{\mathrm{m}} & =\frac{\left(\rho_{\mathrm{o}} b_{\mathrm{o}} U_{0}^{2}\right)_{\min }}{g H_{\mathrm{D}}^{2}\left(\rho_{\mathrm{C}}-\rho_{\mathrm{W}}\right)} \\
& =-\frac{\sin \alpha_{\mathrm{f}}-\sin \alpha_{0}+2-2 \sqrt{\left(1-\sin \alpha_{\mathrm{f}}\right)\left(1-\sin \alpha_{0}\right)}}{2\left(\sin \alpha_{\mathrm{f}}-\sin \alpha_{0}\right)^{2}}
\end{aligned}
$$

being $\alpha_{\mathrm{f}}$ computed from:

$\sin \alpha_{\mathrm{f}}=2.4 \sqrt{\frac{b_{\mathrm{o}}}{H_{\mathrm{D}}}}\left[1-2.56 \times\left(\frac{b_{\mathrm{o}}}{H_{\mathrm{D}}}\right)\right]$

This can be confirmed in the infrared image of the following figure, where it can be observed that $\alpha_{\mathrm{f}} \approx 20^{\circ}$, with $U_{0, \min } \approx 3.0 \mathrm{~m} / \mathrm{s}$. However, in practical terms, setting the curtain for this velocity is not recommended, once it becomes

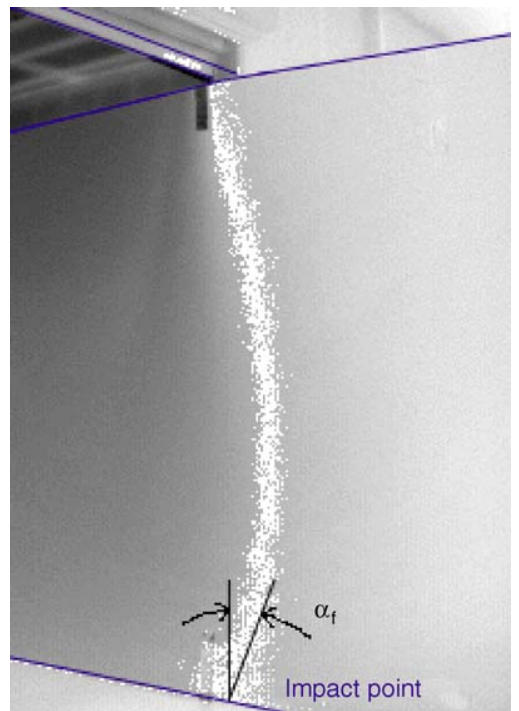

Fig. 7. Example of determination of point and angle of impact on the floor, for a situation with $U_{0}=5.0 \mathrm{~m} / \mathrm{s}, H_{\mathrm{D}}=2.25 \mathrm{~m}, \Delta T=10^{\circ} \mathrm{C}, \alpha_{0}=0^{\circ}$.

very unstable and any exterior perturbation (e.g. a passing person) is enough to change the flow topology, reducing drastically sealing efficiency. Setting the initial velocity of the jet to a value slightly over the critical one $\left(U_{0, \min }\right)$ represents a good compromise (Fig. 7).

An advantage of visualization with an infrared camera is the possibility of registering almost continuously time sequences, which allows analyses of phases with a strong transient character, like curtain start-up. A sequence of temperature
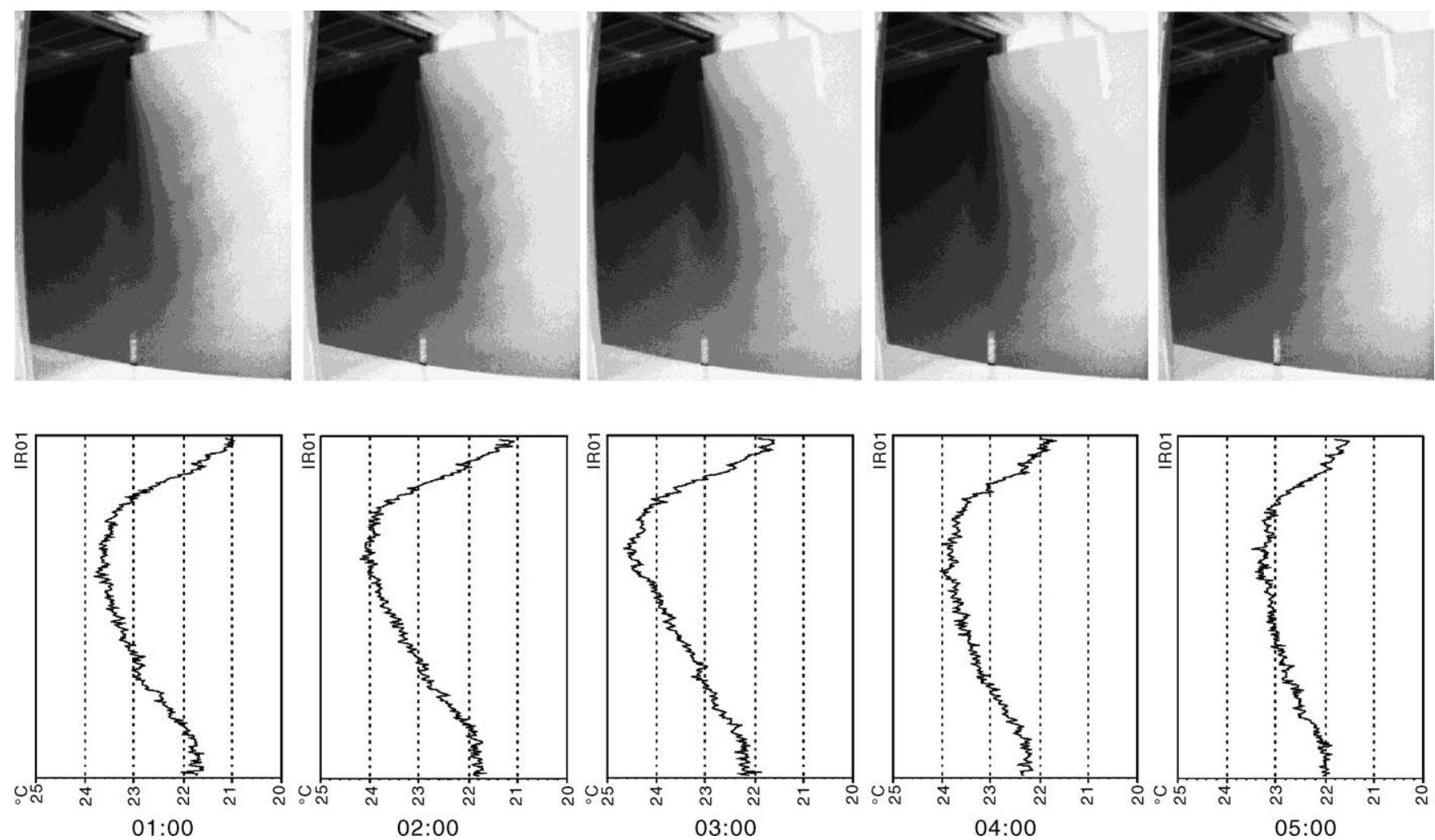

Fig. 8. Evolution of temperature profiles along the central axis of the jet, for a situation where $U_{0}=4.5 \mathrm{~m} / \mathrm{s} ; H_{\mathrm{D}}=2.25 \mathrm{~m} ; \alpha_{0}=0^{\circ}, T_{\mathrm{C}}=16^{\circ} \mathrm{C}, T_{\mathrm{W}}=25{ }^{\circ} \mathrm{C}$. 
profiles, derived from infrared images obtained during the first minutes of operation of the air curtain after it was switched on, are presented in Fig. 8. Analysing the sequence, it is possible to see that there is an adaptation phase before that the equilibrium between the various forces in presence is reached. During this period, significant heat and mass exchanges occur between the two compartments.

\section{Conclusions}

Infrared thermography is a measuring and visualization process that allows obtaining, in real time, very useful images to the understanding of flow topology and temperature field distribution. When compared with point measuring techniques, it is easier to implement and operate than these methods.

Nevertheless there are some problems associated with its use. In practical terms, the measuring screen is intrusive and introduces some perturbation on the analysed flow and there are some constrictions due to the narrow field view of the lens. Also in terms of the liability of the results, the temperature of a point on the measurement screen is not exactly the same as the one of the air in the same location, in the absence of the screen, because the respective thermal capacities are different. Good sharpness of the thermal images requires a minimal temperature difference, due to resolution limitations of the camera thermal sensor.

In the work here presented, it was possible, to afford the behaviour of the curtain air jet in terms of suffered deflection, impact angle on the ground, evolution of the start-up transient phase, temperature gradients in the studied zone, from the images collected through the use of infrared thermography. A parametric study was conducted, being analysed the influences of different variables (door height, temperature difference between two compartments, initial angle and velocity of the jet, etc.) on the sealing effect provided by an air curtain device.

\section{Acknowledgements}

First author gently acknowledges financial support from a doctoral grant given by Programa de Desenvolvimento Educativo para Portugal (PRODEP), Medida 5.1-Formação Avançada no Ensino Superior. Air curtain devices were yielded by the manufacturing firm CENTAURO.

\section{References}

[1] A. Valkeapää, Effect of design parameters of unheated twin air jets on thermal conditions near the doorway, in: Proceedings of RoomVent 2002, Eighth International Conference on Air Distribution in Rooms, vol. 1, Copenhagen, (2002), pp. 677-680.

[2] E.B. Lawton, R.H. Howell, Energy savings using air curtains installed in high-traffic doorways, ASHRAE Transactions 101 (2) (1995) 136-143.

[3] C.C. Downing, W.A. Meffert, Effectiveness of cold-storage door infiltration protective devices, ASHRAE Transactions 99 (1993) 356-366, part 2.

[4] J. Van Male, A new vertical air curtain design for cold-storage doors, in: Proceedings of 16th International Congress of Refrigeration, vol. IV, Paris, (1983), pp. 74-82.

[5] K. Takahashi, M. Inoh, Some measurements on air curtain efficiency for cold rooms, in: Proceedings of 11th International Congress of Refrigeration, vol. II, Munich, (1963), pp. 1035-1039.

[6] J.P. Rydock, T. Hestad, H. Haugen, J.E. Skaert, An isothermal air curtain for isolation of smoking areas in restaurants, in: Proceedings of RoomVent'2000, Seventh International Conference on Air Distribution in Rooms, vol. 1, Reading, (2000), pp. 663-668.

[7] L. Qiang-min, P. Shia-hui, Duck down pollution control with recycle air curtain, in: Proceedings of the Fourth International Symposium on Ventilation for Contaminant Control, Stockholm, (1994), pp. 423-428.

[8] Y.N. Shen, Z. Wang, F.C. Zhang, The characteristic research into the air conditioning umbrella with an air curtain, in: Proceedings of Conference on Cryogenics and Refrigeration, 1998, pp. 286-289.

[9] ASHRAE, Air curtains, 1999 ASHRAE Applications Handbook, vol. 2., Chapter 28, Ventilation of the Industrial Environment, 1999, pp. 28.1828.20 .

[10] M.C. Silva, L.P. Neto, G.V. Brites, Vedação aerodinâmica por cortina de ar-ensaios experimentais, in: Proceedings of I Jornadas Técnicas de Primavera da EFRIARC, Climatização \& Refrigeração em Portugal, Porto, 2001 (in Portuguese).

[11] M. Cehlin, B. Moshfegh, M. Sandberg, Visualization and measurement of air temperature using infrared thermography, in: Proceedings of RoomVent'2000, Seventh International Conference on Air Distribution in Rooms, vol. I, Reading, (2000), pp. 339-347.

[12] Thermovision 550—Manual de Operação, Agema Infrared Systems.

[13] F.C. Hayes, W.F. Stoecker, Design data for air curtains, ASHRAE Transactions 75 (2) (1969) 168-180.

[14] J.J. Costa, L.A. Oliveira, Vedação aerodinâmica: parametrização numérica do isolamento de duas divisões, in: Proceedings of V Congresso de Métodos Numéricos em Engenharia, Madrid, 2002 (in Portuguese).

[15] F.C. Hayes, Heat transfer characteristics of the air curtain: a plane jet subjected to transverse pressure and temperature gradients, Ph.D. Thesis, University of Illinois, USA, 1968.

[16] L.P. Neto, M.C. Silva, Influence of the jet initial inclination angle on the performance of an air curtain device, in: Proceedings of Healthy Buildings 2003, Seventh International Conference on Energy-Efficient Healthy Buildings, Singapore, 2003.

[17] F.C. Hayes, W.F. Stoecker, Heat transfer characteristics of the air curtain, ASHRAE Transactions no. 2120, vol. 75, Part II, 1969. 